\title{
Developmental Versus Language-Based Factors in Metaphor Interpretation
}

\author{
Janice Johnson \\ York University, North York, Ontario, Canada
}

\begin{abstract}
This study examines the respective roles of language proficiency and more general developmental factors (e.g., mental capacity, knowledge) in children's metaphor interpretation. Subjects were Spanish-English-speaking and monolingual-English children from 7 to 12 years of age. The samples were English-speaking middle-class $(n=31)$ and working-class children $(n=34)$ and Spanish-English-speaking children who were either long-term residents $(n=39)$ or recent immigrants to Canada $(n=21)$. These samples were equal in measured mental capacity but differed on measures of language proficiency in English. With a previously validated procedure, subjects' metaphor interpretations were scored for cognitive complexity. Metaphor score increased with age, and the developmental curves were parallel across the four samples. For metaphor score, effects due to language or socioeconomic status were of small magnitude in relation to those due to age.
\end{abstract}

There is a rich body of data describing developmental changes in ability to comprehend metaphors (for reviews see Gardner, Winner, Bechhofer, \& Wolf, 1978; Kogan, 1983; Ortony, Reynolds, \& Arter, 1978; Palermo, 1986; Pollio \& Pickens, 1980; Vosniadou, 1987a; Winner, 1988), much of it focusing on how task factors affect ability to demonstrate metaphoric understanding. Research has shown that preschoolers have some ability to recognize metaphoric relations if the task involves nonverbal responding or simple pairing of stimuli on the basis of metaphoric similarity (Gardner, 1974; Gentner, 1977; Marks, Hammel, \& Bornstein, 1987; Vosniadou \& Ortony, 1983; Vosniadou, Ortony, Reynolds, \& Wilson, 1984; Waggoner \& Palermo, 1989). Ability to comprehend metaphors continues to improve throughout the school years and into adolescence and adulthood (e.g., Asch \& Nerlove, 1960; Billow, 1975; Boswell, 1979; Cometa \& Eson, 1978; Gentner, 1988; Johnson \& Pascual-Leone, 1989; Waggoner \& Palermo, 1989; Winner, Rosenstiel, \& Gardner, 1976). This developmental course is particularly evident when

The research was conducted while Janice Johnson was a postdoctoral fellow in the Development of Bilingual Proficiency Project (DBP), Modern Language Centre, Ontario Institute for Studies in Education, Toronto, Ontario, Canada. The research was supported by a Social Sciences and Humanities Research Council of Canada (SSHRC) research grant to the DBP. Preparation of this article was supported in part by an SSHRC research grant to Janice Johnson.

I thank the members of the DBP-in particular B. Harley, J. Cummins, and $M$. Swain-and acknowledge also the advice of $J$. Pascual-Leone and E. De Avila. I thank the Metropolitan Separate School Board and the students and staff of the participating schools for their cooperation and participation. Comments by $\mathbf{M}$. Schommer and anonymous reviewers were very useful in preparing this article. E. Rivas-Arraiz assisted with testing and scoring; S. Prior assisted with manuscript preparation.

Correspondence concerning this article should be addressed to Janice Johnson, Department of Psychology, York University, 4700 Keele Street, North York, Ontario, Canada M3J IP3. understanding is assessed with tasks that require verbal paraphrase of the metaphoric meaning.

There is a lack of clear evidence regarding the underlying causes of these changes (Gardner et al., 1978; Gentner, 1988; Palermo, 1986; Vosniadou, 1987a; Winner et al., 1976). Such change might be due to developmental increase in domainspecific knowledge (Gentner, 1988; Keil, 1986; Vosniadou et al., 1984; Waggoner \& Palermo, 1989; Winner, 1988), linguistic ability (Vosniadou, 1987a, 1987b; Vosniadou \& Ortony, 1986; Winner, Engel, \& Gardner, 1980; Winner et al., 1976), or general cognitive capacity (e.g., mental-attentional capacity: Johnson, Fabian, \& Pascual-Leone, 1989; Johnson \& Pascual-Leone, 1989; or operational level: Arlin, 1978; Billow, 1975; Cometa \& Eson, 1978). Vosniadou (1987a) concluded that change is caused by interaction of all these factors: "The development of metaphor comprehension is constrained primarily by limitations on children's conceptual knowledge, linguistic skill, and information-processing ability" (p. 880).

In attempting to gauge the relative importance of these three factors in predicting children's metaphor interpretations, the present study focuses in particular on linguistic ability. In this study I used a differential design with subject samples that vary in English linguistic proficiency. Specifically, I used a bicultural developmental design, with children of English home background and children of Spanish home background (i.e., children for whom English is a second language). English proficiency was allowed to vary between groups, but within each age group the children were equated on a nonverbal measure of developmental mental capacity. My goal was to examine possible relationships between language proficiency and metaphor interpretation and to compare the size of any language-group effects with the size of effects due to developmental factors such as age and mental capacity. The presence of social class differences within the monolingual English sample enabled a secondary goal to be undertaken in the study: to examine relationships between metaphor interpretation and cognitive or linguistic differences that are associated with socioeconomic level. 


\section{Relationship Between Linguistic Skill and Metaphor Comprehension}

Vosniadou (1987a) presented a detailed discussion of linguistic factors in metaphor comprehension. One relevant aspect is response mode: Children have generally been found to exhibit better understanding when response involves multiple choice or enactment of the metaphoric meaning, as opposed to verbal interpretation or paraphrase (Pollio \& Pickens, 1980; Vosniadou et al., 1984; Winner et al., 1976; Winner, Wapner, Cicone, \& Gardner, 1979). As have other researchers (e.g., Pollio \& Pickens, 1980; Vosniadou et al., 1984; Winner, 1988), Vosniadou criticized the use of verbal paraphrase to assess metaphor comprehension, claiming that paraphrase places a linguistic load on the child over and above that of tacit metaphor comprehension. She also implicated the following factors in metaphor comprehension: (a) the linguistic form of the metaphoric expression, as the familiarity of the linguistic form and the extent to which it makes explicit the metaphoric comparison can facilitate young children's metaphor comprehension (e.g., Reynolds \& Ortony, 1980; Winner et al., 1980), and (b) the provision of appropriate linguistic context as opposed to decontextualized metaphoric sentences (e.g., Vosniadou et al., 1984; Winner et al., 1980). Finally, Vosniadou (1987a) appealed to children's limited knowledge of words and the concepts they denote (see also Baldwin, Luce, \& Readence, 1982).

The aforementioned conclusions regarding linguistic knowledge and metaphor derive from research relating task factors to developmental trends in metaphor comprehension. There is a small amount of differential research that also implicates linguistic factors in metaphor understanding. Whyte (1983) examined metaphor interpretations of adults who were either normal readers or poor readers. She found no group differences in ability to provide appropriate interpretations but did find differences in the level of language used. Normal readers were more likely to use abstract/psychological referents in their interpretations, whereas poor readers more frequently used concrete/sensory referents.

Nippold and Fey (1983) studied metaphor comprehension in a group of preadolescents (9-11 years) who had a history of language acquisition difficulties. The children had normal general intelligence and performed similarly to a control group on measures of literal language use and comprehension; however, they performed less well than controls on a metaphor paraphrase task. Seidenberg and Bernstein (1986) found that learning disabled children in Grades 3 through 6 performed less well on a multiple-choice metaphor task than did non-learning-disabled controls.

Jones and Stone (1989) examined the ability of language learning disabled and normally achieving adolescents to comprehend contextualized metaphors. Both groups performed better on a multiple-choice version than on a paraphrase version of the task, but controls performed better than language learning disabled subjects regardless of response mode. Jones and Stone reported that the lower performance of the language learning disabled students did not seem to be due to literal word knowledge (they were all able to define the terms used in the metaphors) or to general vocabulary knowledge (metaphor performance was uncorrelated with the Peabody Picture Vocabulary Test in either sample). Rather, Jones and Stone (1989) attributed the results to possible group differences in "knowledge of the more subtle, connotative meanings of words" (p. 257) and suggested that future research examine metaphor comprehension of minority and limited-Englishproficiency samples.

The present study takes this approach. In this study the age variable is detached from the language-skill variable by the use of normally developing subject samples that vary in English linguistic proficiency. The design allows possible relationships with English proficiency to be examined in two ways: by comparison across the language samples (i.e., monolingual English and Spanish-English-speaking samples) and within the Spanish-English-speaking sample. Cummins (1981) claimed that 5 years of residence, on average, are required for immigrant children to approach grade norms on cognitive-academic language proficiency. Length of residence in Canada, therefore, provided a suitable variable on the basis of which to divide subjects into subsamples, for the purpose of examining relationships between English proficiency and metaphor comprehension within the Spanish-English-speaking group.

Spanish-English-speaking children in the present study were bilingual to varying degrees. There is a large and somewhat controversial literature on cognitive effects of bilingualism (e.g., Ben-Zeev, 1977; Diaz, 1983; Hakuta, 1986; Johnson, 1991). It is not the purpose of the present study to examine bilingualism per se as it relates to metaphor interpretation (for such an evaluation, see Johnson, 1989, 1991); however, I address this issue briefly, as follows. One study examined metaphoric understanding in bilinguals and monolinguals: Bountrogianni (1984) examined the performance of Canadian and Canadian-Greek children on a metaphoric triads task (Kogan, 1983) and on a multiple-choice proverb interpretation task in English (all children were born in Canada). The metaphor task measured preference for metaphoric versus nonmetaphoric pairings of pictorial stimuli. There was no group difference on the metaphor task, but the CanadianGreek children showed a greater tendency to choose the moral of a proverb as the best meaning. Bountrogianni suggested that the result may be due to greater use of proverbs in the Greek culture.

On the basis of a theoretical review of the literature on cognitive effects of bilingualism, I have concluded (Johnson, 1991) that consistent performance advantages for bilinguals occur only in cognitive tasks that present a misleading aspect, that is, tasks that create a cognitive conflict between structures needed for correct performance and other structures cued by the situation. In the absence of misleading situational factors, no bilingual advantages are found. The metaphor task used in the present study is not cognitively misleading, and thus there is no reason to predict a bilingual advantage (see Johnson, 1991, for relevant data). A bilingual disadvantage would be expected only to the extent that less well developed linguistic structures (e.g., vocabulary; Ben-Zeev, 1977) might affect performance. 


\section{Social Class Factors in Linguistic Performance}

As mentioned above, the socioeconomic composition of the English-speaking sample in the present study allowed examination of possible social class differences in metaphor interpretation. This variable has not heretofore been studied in the metaphor literature. There is an extensive literature on the relationship between social class and cognitive and linguistic variables, and only broad conclusions from this literature can be presented in this article. Social class and cultural differences in use of language in the home have been documented (e.g., Farran, 1982; Heath, 1982, 1983; Hess, \& Shipman, 1965; Snow et al., 1976; Tough, 1982), as have differences in maternal teaching strategies (e.g., Laosa, 1978, 1980). The current view is that such differences may reflect adaptive responses to differing demands for adult competence in the particular social group (Ogbu, 1981). Nevertheless, the learning styles and the communication styles developed in middle-class homes appear to better match the expectations of the traditional school than do those developed in lowerincome homes. Thus, children from the lower socioeconomic levels often suffer a mismatch between their own competencies and those on which the school expects to build (e.g., Heath, 1982; Ogbu, 1981, 1985; Slaughter-Defoe, Nakagawa, Takanishi, \& Johnson, 1990). With regard to language variables, social class differences generally have not been found for contextualized language skills (i.e., skills related to the conversational use of language; e.g., Dickinson \& Snow, 1987; Wells, 1981). However, middle-class children appear to have an advantage on decontextualized language tasks, that is, language use that relies primarily on linguistic cues to meaning in the absence of a supporting context (Bernstein, 1971; Corson, 1989; Dickinson \& Snow, 1987; Farran, 1982; Feagans, 1982; Holobow, Genesee, Lambert, Gastright, \& Met, 1987; Rackstraw \& Robinson, 1967).

Recent research within a neo-Piagetian framework has attempted to uncover factors that may underlie social class differences in cognitive performances. A central theoretical variable in this approach is the concept of a developmentally increasing mental capacity, that is, a general mental-processing resource, a mental-attentional energy that can be used to boost the activation of task-relevant schemes (knowledge structures) that are not sufficiently activated by the situation (Johnson et al., 1989; Pascual-Leone, 1970, 1984, 1987). In simple terms, mental capacity corresponds to the number of separate pieces of information, not directly activated by the input, that the subject can actively keep in mind at any one time. Such capacity is related to, but not identical to, constructs such as mental effort (Kahneman, 1973) and working memory (e.g., Case, 1985). ${ }^{1}$

Within the neo-Piagetian theory proposed by PascualLeone, mental capacity is seen as increasing maturationally, independent of experience. To the extent that a task is a pure measure of mental capacity, one would expect performance differences to result from age but not from other group factors. To the extent that a task involves other variables, such as content knowledge, strategic knowledge, or information-processing style, group differences due to factors other than age are predicted (Globerson, 1983). Studies of children from different socioeconomic levels, within several cultures, have supported the prediction that social class differences should be absent on sufficiently pure measures of mental capacity but are likely to appear in tasks that allow knowledge or stylistic factors to intervene in performance (Case, 1975; Globerson, 1983; Miller, 1980; Miller, Pascual-Leone, Campbell, \& Jukes, 1989; Pascual-Leone \& Ijaz, 1989). Globerson, for example, examined performance on a range of tasks for Israeli 8 to 12 year olds from low and high social classes. On tasks that confounded capacity with verbal knowledge (i.e., the Vocabulary and Similarities subtests from the Wechsler Intelligence Scale for Children-Revised; raw rather than scaled scores were used because of the interest in age variance), social class accounted for about $17 \%$ of the performance variance, and age group accounted for $27 \%$. By contrast, for performance on "pure" mental capacity tests, social class accounted for no variance, and age group accounted for about $58 \%$ of the variance.

Thus, examination of possible social class differences in performance may also throw light on factors underlying metaphor comprehension. If interpretation of decontextualized metaphors is strongly influenced by language skills and differences in relevant knowledge, then large social class differences should be found. If, however, developmental capacity plays a major role in determining level of metaphor interpretation, then differences due to socioeconomic group should be small relative to those that are due to age group.

In the following passage, I review briefly a model of metaphoric processing (for further detail, see Johnson \& PascualLeone, 1989) and its relationship to the various factors considered in the preceding passages.

\section{A Model of Metaphoric Processing}

In a metaphor, a topic is described in terms of a vehicle (e.g., in "My sister was a rock," the topic sister is compared to the vehicle rock). In comprehending a metaphor, a person selects some semantic aspect or facet of the vehicle's referent (e.g., "physical hardness" for rock) and maps it onto the topic. Mapping refers to some sort of mental transformation that the person applies to the selected vehicle facet to accommodate it to the semantics of the topic. Metaphoric mappings vary as to the degree of transformation in the vehicle meaning. For instance, for the metaphor "My sister was a rock," a response addressing "physical hardness" in the sister (e.g., "She was hard, like if you felt her hand you couldn't squish it or anything") involves less transformation, less accommodation, than does one addressing "psychological hardness" in the sister (e.g., "She was unyielding; she had a hard personality"). A further degree of transformation is evidenced by an

\footnotetext{
${ }^{1}$ Mental capacity is a limited attentional resource that serves to increase the activation of information (i.e., schemes) relevant to the current task performance. Such schemes constitute a subset of information activated in working memory (Pascual-Leone, 1987). The information that momentarily constitutes working memory may have sources of activation other than mental-attentional capacity (e.g., overlearning or perceptual support from the current context).
} 
instantiation or conceptualization of the mapped facet in terms relevant to the topic but not to the vehicle (e.g., "The sister was mean").

According to this model, developmental change in metaphor interpretation reflects increasing ability to perform higher level transformations. Levels (i.e., degrees) of transformation are conceptualized theoretically as kinds of mentalmapping operators that the subject can use to generate interpretations. Other researchers (e.g., Gentner, 1988; Tourangeau \& Sternberg, 1982) have proposed that metaphor comprehension requires mental mapping. The current model contributes the notion of developmentally ordered kinds of metaphoric mappings. The levels of transformation are not intended necessarily to correspond to degrees of "correctness" in metaphor interpretation. The levels correspond rather to degrees of change in the meaning of the vehicle facets as they apply to the topic, in the process of interpretation. The levels are ordered in terms of their proposed cognitive complexity and their empirical order of emergence in childhood (Johnson \& Pascual-Leone, 1989).

\section{Factors Affecting Level of Metaphor Interpretation in Childhood}

I have been considering three factors that might underlie developmental change in metaphor interpretation. One of these, increasing linguistic skill, is discussed in the preceding passages. Research has suggested that the linguistic factor may be particularly relevant when metaphor comprehension is assessed by means of verbal paraphrase, as it is in the present study. A second factor is domain-specific knowledge: Mental referents for the topic and especially the vehicle terms are essential for understanding. Some researchers have claimed that increase in domain-specific knowledge is, in fact, the primary cause of change in metaphor interpretation in childhood (Gentner, 1988; Keil, 1986; Vosniadou et al., 1984; Winner, 1988).

Elsewhere, I have argued for a third necessary factor: a general cognitive capacity that places a developmental constraint on the level of interpretation (Johnson, 1989; Johnson et al., 1989; Johnson \& Pascual-Leone, 1989). Using PascualLeone's method of task analysis (e.g., Pascual-Leone, 1980; Pascual-Leone \& Goodman, 1979; Pascual-Leone \& Johnson, in press), I have estimated the mental capacity demand (i.e., the cognitive-developmental complexity) of various kinds of metaphoric transformations (i.e., mapping operators; Johnson \& Pascual-Leone, 1989). In brief, the greater is the degree of transformation, the higher is the mental demand of generating the interpretation. This is because higher levels of transformation require a person to "keep in mind" more semantic aspects of the topic (so as to accommodate the vehicle facets more closely to the topic). I have used these complexity estimates to construct a quantitative scale of metaphoric processing. This scale has been shown to have good reliability and developmental validity for samples of English-speaking Canadian and American children (Johnson, 1987; Johnson et al., 1989; Johnson \& Pascual-Leone, 1989). Elsewhere (Johnson et al., 1989; Johnson \& Pascual-Leone, 1989), I have presented evidence in support of the claim that level of metaphor interpretation is constrained by the child's stage of mental capacity.

Theoretically, mental capacity increases maturationally, whereas increases in linguistic skill and domain-specific knowledge are mediated by experience. The aim of the current study is to compare, for metaphor interpretation, the size of effects due to developmental factors (represented by age group) with those due to language proficiency (represented by language group). Attempts were made in the study to control for the effects of domain-specific knowledge. To this end, I used topic and vehicle terms, the referents of which were familiar to all subjects (all the children were able to define the terms). In addition, I did not score interpretations in terms of "correctness" or agreement with adult interpretations but rather in terms of the degree of semantic transformation underlying the interpretations. Thus, the same complexity measure could be applied across contents, which limited the confounding of complexity level with content knowledge. Nevertheless, subject differences in richness of relevant domain-specific knowledge were not completely controlled. For this reason, age in the present study must be seen as representing an increase in both capacity and knowledge.

If developmental level is more important than linguistic skill in determining level of metaphor interpretation, then (a) the same developmental pattern of metaphor comprehension should occur across language groups, that is, in monolingual English and in Spanish-English-speaking children; this would provide evidence for a developmental factor independent of linguistic ability; and (b) the percentage of variance accounted for by age group should exceed that accounted for by language group. The same hypotheses should hold for comparisons within the Spanish-English-speaking sample when it is subdivided according to length of residence in Canada.

Similar hypotheses are made for the social class comparison within the English-speaking sample. If mental capacity is a major constraint on performance level, then developmental trends in metaphor interpretation should be similar across social classes, and social class should account for less variance than should age group.

\section{Method}

\section{Subject Selection}

Children with Spanish or English as their home language were recruited from Grades 2, 4, and 6 from three schools in working-class areas of Toronto, Ontario, Canada; these schools were selected because they had a large enrollment of Spanish-English-speaking students. The children were tested with the Figural Intersections Test (FIT; described below), a nonverbal measure of mental capacity.

To ensure normal developmental samples, subjects were selected who demonstrated measured mental capacity within the normal range for their age group, as defined by Pascual-Leone's norms (PascualLeone, 1970; Pascual-Leone \& Goodman, 1979). Subjects were selected who obtained a FIT score within one mental unit of the theoretically predicted, and usually found, capacity measure for their age (e.g., the predicted measured capacity of 7 year olds and 8 year olds is three mental units; thus, those 7 year olds and 8 year olds who were selected had a FIT score of 2,3 , or 4 ). As previously mentioned, 
mental-attentional capacity is measured in terms of schemes (i.e., discrete knowledge structures); a mental unit is a scheme. Subjects were divided into three age groups: 7-8 years, 9-10 years, and 11-12 years. Further criteria for selection of Spanish-English-speaking subjects were that Spanish be the subjects' first language, that the subjects' parents speak Spanish at home often or always, and that the subjects speak Spanish at home at least sometimes (this information was obtained from a questionnaire completed by parents). A further criterion for English-speaking children was that English be the only language spoken by both the children and their parents, that is, the English-speaking sample was selected to be monolingual.

Twenty Spanish-English-speaking children per age group met the abovementioned criteria; this represented $70 \%$ of the initial pool of Spanish-English-speaking children. The schools were in ethnically mixed communities, and a minority of the students were monolingual English speakers. Children who met the criteria for the Englishspeaking sample ( $n=34$ ) were matched with Spanish-English-speaking subjects, but it was not possible to obtain an equal-sized sample of monolingual English children from the same schools. This necessitated recruiting from a fourth school in a less ethnically mixed, more middle-class area to obtain additional monolingual English children $(n=26)$. Monolingual English children in Grades 2, 4, and 6 were tested with the FIT and added to the pool of English-speaking subjects. The final sample consisted of 20 Spanish-English-speaking and 20 monolingual English children in each of the three age groups; within age group the two language samples were matched on age and FIT score. Each sample contained 34 girls and 26 boys. Differences within the English-speaking sample are examined in the EnglishSpeaking and Spanish-English-Speaking Subsamples subsection of the Results and Discussion section.

Of the Spanish-English-speaking children, $58 \%$ were born in Canada to families of South American or Central American ancestry. Of the remaining $42 \%, 40 \%$ were immigrants from Central America (specifically, El Salvador and Guatemala) and $60 \%$ were immigrants from South America (Argentina, Chile, Ecuador, and Peru). Data on the ethnic origins of the English-speaking subjects were not sought.

\section{Measurement of Mental Capacity}

The FIT (Pascual-Leone \& Ijaz, 1989; Pascual-Leone \& Smith, 1969 ) is a group-administered, paper-and-pencil measure. Each of the 36 items consists of two presentations of a number of geometric shapes: The shapes are printed separately on the right-hand side of the page and in an intersecting configuration on the left-hand side. Items vary, consisting of from two to eight shapes, and the number of shapes defines the class of the item. Subjects are instructed to locate in the intersecting configuration the one area in which all shapes from the right-hand side overlap. The FIT score corresponds to the highest item class that the subject passes reliably (i.e., $75 \%$ correct), given similarly reliable passing on all lower classes. The score thus reflects the maximal number of shapes the subject can simultaneously "keep in mind."

Analysis of FIT data from several studies yields reliability estimates in the mid .80s to the low .90s (De Avila, Havassy, \& Pascual-Leone, 1976; Johnson, 1982; Pascual-Leone \& Burtis, 1975). The test correlates with chronological age, mental age, and other measures of mental-attentional capacity (De Avila et al., 1976; Johnson, 1982; Parkinson, 1975); it has been found to predict level of scientific reasoning (Niaz \& Lawson, 1985) and performance on Piagetian tasks (de Ribaupierre \& Pascual-Leone, 1979; Parkinson, 1975). The FIT is relatively insensitive to social class differences (De Avila et al., 1976; de Ribaupierre \& Pascual-Leone, 1979; Miller, 1980; Miller et al., 1989; Pascual-Leone \& Ijaz, 1989). Although the FIT shares neither content nor method variance with the metaphor task, I propose that performance level on both tasks is constrained by the mental-attentional capacity of the child.

\section{Measurement of Oral Language Proficiency}

One measure of language proficiency used was the Oral Language subscale of the Woodcock Language Proficiency Battery (Woodcock, 1980, 1981); English and Spanish versions were used. The Oral Language subscale consists of three subtests to which the child responds orally: picture vocabulary, antonyms/synonyms, and verbal analogies. The subscale measures "vocabulary comprehension, conceptualization, and expression (i.e., the ability to understand the meaning of words, to conceptualize the relationships of words, and to define words)" (Hessler, 1982, p. 98). The test yields a summary score for the subscale (called the oral cluster score by Woodcock; henceforth referred to in this study as the Woodcock summary score) and a standard score (based on a mean of 100 and a standard deviation of 15; henceforth referred to as the Woodcock standard score). The Woodcock summary score retains age variance; the Woodcock standard score does not. Language-group differences are expected to be maximized on the standard score, and thus this score was used to characterize groups in terms of proficiency level. The summary score was used in correlational analyses, in which the additional developmental variance was of interest.

A second language proficiency measure was a story-retelling task taken from the Language Assessment Scales (LAS; De Avila \& Duncan, 1983). Children listened to a short tape-recorded story and then were asked to retell the story orally in their own words; throughout, the children looked at cartoon pictures illustrating the story. In retelling the story, the child transforms it into his or her own words and syntactic structures, thus yielding a sample of his or her oral production skills in the test language. Different stories were presented in English and Spanish. The stories were scored on a 6-point scale measuring level of oral-productive proficiency (De Avila \& Duncan, 1983). A score of 0 indicates a nonspeaker, and a score of 5 indicates a proficient speaker. Scoring criteria focus on vocabulary and syntactic complexity; the criteria are adjusted for age. A Spanish-Englishspeaking scorer and an English-speaking scorer achieved an interrater reliability of $90 \%$ on a sample of English stories before individually scoring stories in the appropriate language.

In addition, the classroom teachers used the Observation Form from the LAS (De Avila \& Duncan, 1983) to rate the English proficiency of the Spanish-English-speaking students. Seven-point scales $(-3$ to +3$)$ were used to rate proficiency in 10 areas: ability to communicate in English in five different situations (e.g., explaining how to play a game) and skill in pronunciation, comprehension, vocabulary, syntax, and general communicative competence. The 10 ratings were averaged to obtain an overall score. The story-retelling and teacher-rating measures are expected to provide fairly pure estimates of fluency in English. By contrast, the Woodcock scores may confound somewhat oral proficiency and general knowledge.

\section{Measurement of Metaphor Interpretation}

Metaphor task. The main dependent variable was score on a metaphor interpretation task. Children were asked to interpret orally in English each of 11 ambiguous metaphors. Data are reported on 6 of the metaphors that have been used in previous research; the additional metaphors were practice or filler items. The metaphor items were constructed by combining, in a " was a sentence frame, each of two topics ( $m y$ sister and $m y$ shirt) with each of three vehicles (mirror, rock, and butterfly), to form metaphors such as "My sister was a mirror" and "My shirt was a rock." 
Subjects were first asked to define the nouns used in the metaphors. All the children were familiar with the terms and their meanings. Such a technique guarantees that children know the lexical items and their referents, which is necessary for interpretation of the metaphors. However, the technique of asking the children to define the terms leaves language proficiency free to play a role in the construction (e.g., through linguistic association) and the expression of the child's interpretation. It is mainly in the expression of the metaphoric meaning (i.e., the need to convey the interpretation verbally through use of appropriate lexical terms and grammatical structure) that other researchers have proposed that linguistic ability might have an effect. After requesting the definitions, the tester read each metaphor item aloud and asked the subject to give a possible meaning. Subjects sometimes gave more than one meaning for an item; in this case, they received credit for their highest level spontaneous response. The interviews were tape-recorded for later transcription, and the transcripts were used in coding the interpretations. No identifying or other information on the subjects appeared on the transcripts; thus, the coding was done without regard to the subjects' age and language group.

Coding of metaphor interpretations. Subjects' metaphor interpretations were coded in terms of vehicle facets and mapping operators, according to a previously validated procedure (Johnson et al., 1989; Johnson \& Pascual-Leone, 1989). As mentioned previously, facets are semantic aspects of the vehicle's referent (e.g., "physical hardness" for rock), and mapping operators are kinds of mental transformations the subject may apply to these facets to generate interpretations. The code yields five categories or levels of metaphoric mapping; these are described in detail by Johnson and Pascual-Leone (1989). I give brief descriptions of the categories in the following paragraphs, using as examples responses to the item "My shirt was a rock."

The lowest level category contains inappropriate responses. These are interpretations that do not make a mapping from vehicle to topic (e.g., "Maybe the shirt laid over a rock") or that violate the semantics of the topic (e.g., "It would mean it was a rock carved out like a shirt"). The next category (which I call identity) corresponds to a lowlevel metaphoric mapping. In this case the facet selected from the vehicle is mapped onto the topic without any change of meaning (e.g., "The shirt was hard"). For a response to be scored as an identity, the mapped facet(s) must potentially be compatible with the semantics of the topic.

The analogy category is an intermediate level of metaphoric mapping. In this case the selected vehicle facets undergo a change in sense as they apply from vehicle to topic. This change represents an accommodation of the vehicle facets to the semantics of the topic, as in "My shirt might be stiff." In this response the vehicle facet (i.e., "physical hardness") has been "softened" a bit, so that it is more applicable to a shirt. In an analogy mapping, the vehicle facet and the (semantically different) topic facet it maps are subsumed by a higher level, generic facet; for this example, the generic facet would be a tendency not to yield.

The predicate category involves an elaboration of the mapped facet(s) by means of a concept or an instantiation that is relevant to the topic but not to the vehicle. A first level of predication (the experiential predicate) involves description of a topic-relevant instance; for example, "The shirt might have went stiff if you left it outside when it was wet in the winter." In this response the subject relates a topic-relevant example of how a shirt could come to have the mapped facet. Such a response is cued by the generic facet (e.g., tendency not to yield), but it moves beyond simple description of this generic facet (i.e., beyond the analogy level) to describe a situation fairly unique to the domain of shirts.

The conceptual predicate category corresponds to a higher level of predication. At this level the elaboration is made in terms of a topicrelevant concept, that is, in terms of a type of the topic as in "The shirt was starchy." "Starchy" is a concept that is properly based on the generic facet, but the response moves beyond the shared generic facet to describe a type of shirt that could possess that facet.

These five levels represent progressive accommodations of the vehicle facets to the semantics of the topic. They also reflect an order of increasing mental demand. Johnson and Pascual-Leone (1989) presented task analyses of the mental capacity demands of constructing interpretations at each of the levels. They also presented data that agree with developmental predictions derived from the results of the task analyses. In a sample of monolingual English speakers (children 6 through 12 years of age and adults; $N=186$ ), Johnson and PascualLeone (1989) found that not until 7-8 years of age did children reliably produce interpretations that were at least identities, not until 9-10 years of age did they reliably produce responses that were at least analogies, and not until 11-12 years of age did they reliably produce predicates. A reliable level of responding was considered to be at least $50 \%$ of interpretations. Adults reliably responded at the conceptual predicate level.

Interrater agreement on metaphor coding was $86 \%$ for a random sample of transcripts. Quantitative scores were assigned to the coded interpretations: a score of 1 for inappropriate responses, 2 for identities, 3 for analogies, 4 for experiential predicates, and 5 for conceptual predicates. These quantitative scores have been validated in previous research in which metaphor score was found to increase with age cohort in a predictable manner and to correlate highly with age, mental age, and measures of mental capacity (Johnson et al., 1989; Johnson \& Pascual-Leone, 1989). Test-retest reliability for a group of 7 to 12 year olds was .81 (.62 with age partialed out; Johnson, 1989).

\section{Procedure}

The children were first tested in class groups with the FIT. For the Spanish-English-speaking children and their English-speaking classmates, FIT instructions were given in English and Spanish. Instructions were given only in English to the English-speaking subjects from the fourth school. The selected subjects were tested individually in English with the metaphor task and the Woodcock and story-retelling measures of oral language proficiency. Two to 3 weeks later the Spanish-English-speaking subjects were tested further with the Spanish language-proficiency measures.

\section{Results and Discussion}

\section{Full English-Speaking and Spanish-English-Speaking Samples}

Results are examined first for the full English-speaking and Spanish-English-speaking samples. In a later section, results are presented for subsamples partitioned according to socioeconomic status and length of residence in Canada. In the analyses that follow, all nonreported $F_{8}$ had associated $p s>$ .05. All multiple comparisons, carried out after analyses of variance were performed, were conducted with Tukey's Studentized range (honestly significant difference; HSD) test.

Subject variables: Oral-language proficiency and mental capacity. Performances on the various language proficiency measures were examined first to check for the expected group differences in English proficiency. Monolingual English children $(M=102, S D=10.1)$ scored higher than did the Spanish-English-speaking children $(M=84.7, S D=13.5)$ on the English Woodcock standard score, $F(1,114)=63.97, p$ 
$<.001, M S_{\mathrm{e}}=145.27$. There was no effect of age group on this score, $F<1$. English-speaking children $(M=4.5, S D=$ $0.57)$ scored better than did Spanish-English-speaking children $(M=3.5, S D=0.97)$ on the English LAS story-retelling task, $F(1,114)=50.82, p<.001, M S_{\mathrm{e}}=0.59$. There was also a main effect for age group on this score, $F(2,114)=4.36, p$ $<.02$, with 7 to 8 year olds $(M=3.7)$ scoring reliably $(p<$ $.05)$ lower than 11 to 12 year olds $(M=4.2) ; 9$ to 10 year olds $(M=4.0)$ did not differ from the other two age groups. There were no interaction effects for the abovementioned language measure, $p s>.20$. The teachers of the SpanishEnglish-speaking children had rated the children's English proficiency on a scale ranging from -3 to +3 . There was no age effect for this rating, $p>.20$; mean rating for the sample was $0.98(S D=1.61)$.

For the mental capacity score, FIT, there was an effect for age, $F(2,114)=75.77, p<.001, M S_{\mathrm{e}}=0.55$, but there were no language or interaction effects, $F \mathrm{~s}<1$. The mean FIT scores were $3.0(S D=0.88), 4.3(S D=0.72)$, and $5.0(S D=$ $0.57)$ for the age groups 7-8 years, 9-10 years, and 11-12 years, respectively. Thus, as expected, the English-speaking and Spanish-English-speaking samples differed on oral language proficiency in English but not on mental capacity, measured nonverbally.

Dependent variable: Metaphor comprehension. If linguistic ability does not play a major role in determining level of metaphor interpretation, then the relationship between age group and metaphor performance should be the same for both samples, and the magnitude of any language group effect should be small relative to the effect for age group. To test these hypotheses, a 3 (age) $\times 2$ (language group) $\times 2$ (topic) $\times 3$ (vehicle) analysis, with repeated measures on topic and vehicle, was performed on the quantified metaphor score. In this analysis topic refers to the two topics (sister and shirt), and vehicle refers to the three vehicles (rock, mirror, and butterfly). These task factors were included because previous research has shown item differences in level of interpretation (Johnson \& Pascual-Leone, 1989).

Analysis of between-groups variance yielded main effects for age, $F(2,114)=82.44, p<.001, M S_{\mathrm{e}}=2.29$, and language group, $F(1,114)=9.47, p<.001$. Performance of each age group differed reliably $(p<.05)$ from that of each other age group; the metaphor means for age groups 7-8 years, 9-10 years, and 11-12 years, respectively, were $1.62(S D=0.64)$, $2.79(S D=0.73)$, and $3.36(S D=0.52)$. English-speaking subjects $(M=2.76, S D=0.99)$ performed better than did Spanish-English-speaking subjects $(M=2.42, S D=0.91)$. Of particular interest was the percentage of variance accounted for by each of these effects (eta squared). Age group accounted for $57 \%$ of the between-groups variation in metaphor interpretation; by contrast, language group accounted for only $3 \%$.

Analysis of within-groups variance yielded a main effect for vehicle, $F(2,228)=31.70, p<.001, M S_{\mathrm{e}}=0.95$, and interactions for Age $\times$ Topic, $F(2,114)=3.43, p<.05, M S_{\mathrm{e}}$ $=0.96$, and Age $\times$ Language Group $\times$ Topic, $F(2,114)=$ $4.47, p<.05$. Performance was best on items with the rock vehicle (an effect also found in previous research; Johnson \& Pascual-Leone, 1989). Consistent with earlier findings (Johnson \& Pascual-Leone, 1989), for the Spanish-English-speaking sample only, the youngest children performed better with shirt-topic items than with sister-topic items; this effect was reversed for the older age groups. Analysis of simple effects showed that Spanish-English-speaking subjects $(M=2.29$, $S D=0.76)$ performed less well than English-speaking subjects $(M=2.76, S D=1.04)$ on shirt-topic items only, $F(1,114)=$ $15.52, p<.001, M S_{\mathrm{e}}=0.43$; the two groups performed at the same level on sister-topic items, $p>.10$. There was no Age $\times$ Language Group interaction for the shirt items, $p>.20$, indicating that the language effect was consistent across ages. On shirt items, the percentage of variance explained by language group (6\%) remained small compared with that explained by age group (46\%).

The relationships between metaphor and measures of capacity and linguistic proficiency in English were further examined in correlational analyses. Correlations based on all 120 subjects indicated a strong relationship between level of metaphor interpretation and each of the subject measures that contained developmental variance. These correlations are .74, .63 , and .64 for level of metaphor with chronological age, FIT, and English Woodcock summary score, respectively ( $p$ $<.01)$. The correlation with Woodcock standard score $(r=$ .15) did not differ significantly from zero, and the correlation with the English LAS story-retelling task was moderate ( $r=$ $.34, p<.01$ ). Given the nature of the Woodcock measure, the Woodcock summary score is likely to reflect variance due to mental capacity and general knowledge, as well as linguistic proficiency. This inference can be evaluated statistically. The nonverbal mental capacity measure (FIT) shares neither content nor method variance with the metaphor measure, and in terms of its underlying semantics the FIT is a purer measure than the Woodcock summary score. When mental capacity score was partialed out, the correlation between the Woodcock summary score and the metaphor score was reduced to $.45(p<.01)$; both capacity and language-relevant knowledge appear to contribute to metaphor interpretation.

Similar correlational patterns were revealed when the English-speaking and Spanish-English-speaking samples were examined separately ( $n=60$ each). Correlations between the metaphor score and (a) age, (b) the FIT score, and (c) the English Woodcock summary score were $.74, .56$, and .67, respectively, for the monolingual English sample and .78, .72, and .62, respectively, for the Spanish-English-speaking sample (all $p s<.01$ ). When FIT score was partialed out, the correlation between the Woodcock summary score and the metaphor score was $.50(p<.01)$ for the English-speaking sample and $.32(p<.05)$ for the Spanish-English-speaking sample. Metaphor correlated with the English LAS story retelling task only for the Spanish-English-speaking sample $(r=.39, p<$ $.01)$.

The results suggest that linguistic factors do play a role in metaphor interpretation: There was a main effect for language group in the analysis of variance, and the story-retelling measure of language proficiency correlated moderately with the metaphor measure. Results further suggest, however, that the role of language proficiency is secondary to that played by more purely developmental factors: The language-group effect was restricted to shirt-topic items; the size of the agegroup effect was much larger than that of language group, 
and the subject measures retaining developmental variance correlated more highly with metaphor than did those from which developmental variance was removed, that is, (a) the Woodcock standard score (b) and the Woodcock summary score with FIT score partialed out. Problematic, however, is that, in comparisons of the English-speaking and SpanishEnglish-speaking samples, language group is confounded with socioeconomic group: The English-speaking subjects came from both working-class and middle-class areas, whereas the Spanish-English-speaking subjects came only from workingclass areas. To eliminate this confounding and to examine possible effects of proficiency differences within the SpanishEnglish-speaking sample, further analyses were conducted on appropriately partitioned subsamples.

\section{English-Speaking and \\ Spanish-English-Speaking Subsamples}

Subject variables: Oral-language proficiency and mental capacity. In forming the English-speaking subsamples, children who were schoolmates of the Spanish-English-speaking subjects were assigned to the working-class group; those attending the school in the middle-class neighborhood were assigned to the middle-class group. Five children had been tested at the middle-class school who had not been selected for the original English-speaking sample. These children were now included to increase the size of the middle-class subsample. The middle-class English-speaking subsample contained 31 children ( $n=10, n=10$, and $n=11$ in age groups 7-8 years, 9-10 years, and $11-12$ years, respectively); the workingclass English-speaking subsample contained 34 children $(n=$ $11, n=14$, and $n=9$ in age groups 7-8 years, 9-10 years, and $11-12$ years, respectively).

Data relevant to socioeconomic status had not been collected on the individual children. However, results of a Canadian census (Statistics Canada, 1988) provided data on income levels for the year in which the study was conducted. These data allow for a characterization of the subsamples as groups but not of the individuals within the subsamples. Data on average family income were examined for the census tracts (i.e., homogeneous neighborhoods) in which each of the four schools was located. Weighting the income measure by the number of subjects from the particular census tract, average family income can be estimated as $\$ 33,600$ for the workingclass subsample and $\$ 62,800$ for the middle-class subsample. For the same year, average family income for large population centers in Ontario was $\$ 44,700$. Census data were also available for educational levels. For the census tracts being characterized in this study as working class, $26 \%$ of the population over 14 years of age had less than a ninth-grade education, whereas $10 \%$ had some university education; for the census tract being characterized as middle class in this study, these percentages were $4 \%$ and $44 \%$, respectively.

The research literature suggests that working-class children often score less well than middle-class children on measures of decontextualized language use. Consistent with this finding, a 3 (age) $\times 2$ (socioeconomic status, SES) analysis of variance on the Woodcock standard score yielded a main effect for
SES group in the English-speaking sample, $F(1,59)=14.96$, $p<.001, M S_{\mathrm{c}}=84.55$ (see Table 1 for means). SES group accounted for $18 \%$ of the variance (a finding identical to Globerson's, 1983). Consistent with previous findings for conversational language measures (Dickinson \& Snow, 1987; Wells, 1981) was the absence of an SES effect for the LAS story-retelling task, $F<1$ (see Table 1).

Within the Spanish-English-speaking sample, there were children who were recent immigrants to Canada, as well as children who were long-term residents or who had been born in Canada. It was expected that proficiency level in English would be related to length of residence (cf. Cummins, 1981). Children who had resided in Canada 3 years or less were assigned to a recent-immigrant subsample $(n=8, n=6$, and $n=7$ in age groups 7-8 years, $9-10$ years, and $11-12$ years, respectively); those who had been in Canada at least 5 years were assigned to a long-term resident subsample $(n=12, n=$ 14 , and $n=13$, for the three age groups, respectively). Sample size in the recent-immigrant group is small, and nonsignificant results associated with this subsample should be interpreted with caution.

I conducted 3 (age) $\times 2$ (residency group) analyses of variances on the language measures that had been administered only to the Spanish-English-speaking subjects. As expected, teacher rating of English proficiency was higher for those Spanish-English-speaking children who had resided in Canada at least 5 years, $F(1,54)=16.85, p<.01, M S_{\mathrm{e}}=$ 2.00 . By contrast, recent immigrants performed better than long-term residents on the Spanish Woodcock standard score, $F(1,54)=13.04, p<.001, M S_{\mathrm{e}}=179.59$, and on the LAS story retelling task in Spanish, $F(1,54)=5.94, p<.05$, $M S_{\mathrm{e}}=0.53$. Relevant means appear in Table 1.

Differences across the four subsamples were tested with 3 (age) $\times 4$ (group) analyses of variance, followed by Tukey multiple comparisons $(p<.05)$; means appear in Table 1 . Age effects were consistent with those reported above for the full-sample analyses; there were no interaction effects (all $F$ s $<1)$. The mean English Woodcock standard score of each subsample differed from the means of each other subsample, $F(3,113)=45.36, p<.001, M S_{\mathrm{e}}=106.75$. On the English LAS story-retelling task, each English-speaking subsample performed better than the Spanish-English-speaking subsamples, $F(3,113)=24.39, p<.001, M S_{c}=0.53$, and within the Spanish-English-speaking group, long-term residents performed better than recent immigrants. There were no subsample differences, however, on age and or on the mental capacity measure (all $F s<1$ ). Thus, the subsamples differed on language-relevant variables but not on developmental capacity.

Dependent variable: Metaphor comprehension. I had predicted that the same developmental pattern of metaphor interpretation would be found across subsamples. Figure 1 shows the relation between age and mean metaphor score for each subsample. The curves appear to be parallel, and for all subsamples older children perform better than younger children. This pattern is consistent with the hypothesis that some general developmental factor constrains metaphor comprehension across gkoups.

I used a series of 3 (age) $\times 2$ (group) $\times 2$ (topic) $\times 3$ (vehicle) analyses of variance to evaluate predictions for pairs of sub- 
Table 1

Mean Subject Variable Scores by Age Group for English-Speaking and Spanish-English-Speaking Subsamples

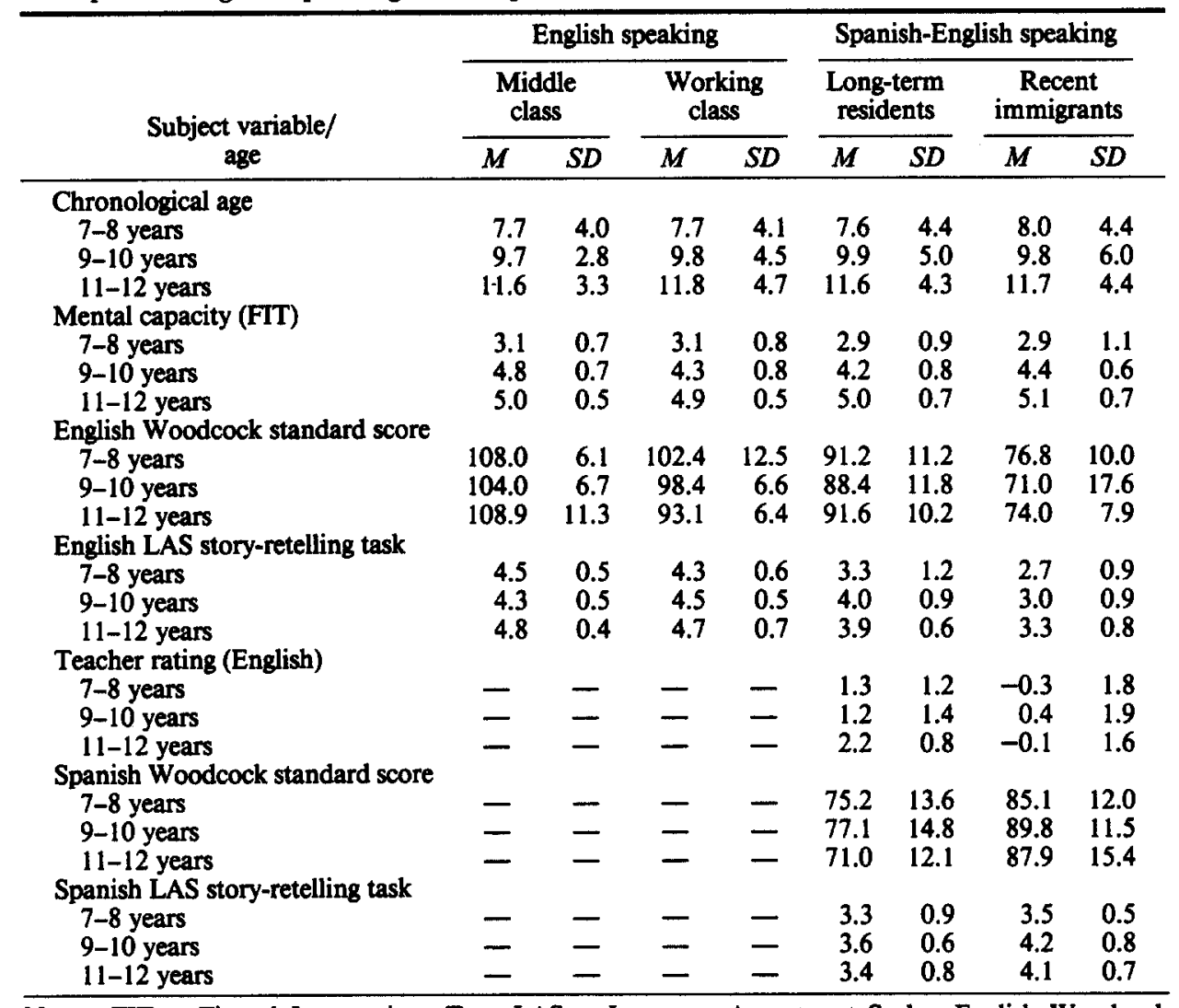

Note. $\quad$ FIT $=$ Figural Intersections Test; LAS = Language Assessment Scales. English Woodcock standard scores were obtained from the oral language subscale of the Woodcock Language Proficiency Battery, English form, and Spanish Woodcock standard scores were obtained from the oral language subscale of the Woodcock Language Proficiency Battery, Spanish form. The story retelling task is from the Language Assessment Scales. The teacher rating is the teachers' rating obtained on the observation form of the Language Assessment Scales.

samples. I had predicted that for each comparison, group effects would be small in relation to age effects. Analysis of metaphor performance in the two English-speaking subsamples yielded main effects for age, $F(2,59)=33.71, p<.001$, $M S_{\mathrm{e}}=2.74$; SES, $F(1,59)=7.38, p<.01$; and vehicle, $F(2$, 118) $=18.51, p<.001, M S_{\mathrm{e}}=1.19$; plus a Topic $\times$ SES interaction, $F(2,59)=4.33, p<.05, M S_{c}=0.90$. Tukey HSD tests indicated that each age group differed from each other age group $(p<.05)$. Children from the middle-class group $(M=3.07)$ performed better than those from the workingclass group $(M=2.56)$. As before, performance was best on items with the rock vehicle. Analysis of simple effects revealed that the SES effect was confined to items with the sister topic, $F(1,59)=11.38, p<.01, M S_{c}=0.61(M=2.5, S D=1.1$, for the working-class subsample and $M=3.2, S D=1.0$, for the middle-class subsample). Of main interest is the relative size of the between-groups effects. For overall metaphor score, age group accounted for $50 \%$ of the between-groups variation, whereas SES group accounted for $5 \%$ of the variance. For sister-topic items, age group accounted for $42 \%$ of the variance, and SES accounted for $9 \%$ of the variance.
The effects of English-language exposure within the Spanish-English-speaking sample were examined by comparing recent immigrants with long-term residents. There were no main or interaction effects involving length of residence (all $p s>.20)$; there was an effect for age, $F(2,54)=44.72, p<$ $.001, M S_{e}=1.91$. Age group accounted for $62 \%$ of the between-groups variation. Again, each age group differed from the others $(p<.05)$. Within-groups effects were consistent with those reported for the full-sample analysis.

Cross-language comparisons are best made between the Spanish-English-speaking subsamples and their Englishspeaking schoolmates; such analyses separate language group and SES group. When the group factor was English-speaking working-class versus Spanish-English-speaking long-term residents, effects occurred only for age, $F(2,67)=46.84, p<$ $.001, M S_{\mathrm{e}}=2.43$, and vehicle, $F(2,134)=18.63, p<.001$, $M S_{\mathrm{e}}=0.99$; there were no effects for language group (all $p \mathrm{~s}$ $>.05$ ). Age group accounted for $58 \%$ of the between-groups variation.

When the group factor was English-speaking working-class versus Spanish-English-speaking recent immigrants, there 


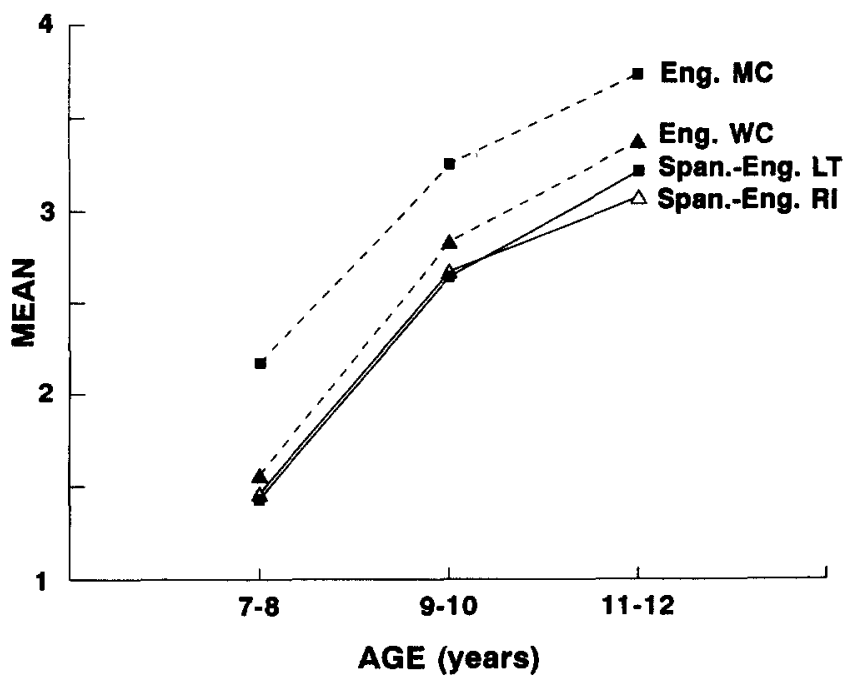

Figure 1. Mean metaphor score as a function of age and subsample. (Eng. $\mathrm{MC}=$ English-speaking middle class; Eng. $\mathrm{WC}=$ Englishspeaking working-class; Span.-Eng. LT = Spanish-English-speaking long-term residents of Canada [5 years or more]; Span.-Eng. RI = Spanish-English-speaking recent immigrants to Canada [ 3 years or less].)

were again effects for age, $F(2,49)=35.19, p<.001, M S_{\mathrm{e}}=$ 2.32 , and vehicle, $F(2,98)=12.11, p<.001, M S_{\mathrm{e}}=1.16$. There was also a Language Group $\times$ Topic interaction, $F(1$, $49)=8.20, p<.01, M S_{\mathrm{e}}=0.80$. Analysis of simple effects showed that English-speaking subjects performed higher than Spanish-English-speaking subjects on shirt-topic items only, $F(1,49)=6.88, p<.05, M S_{\mathrm{e}}=0.43$. Age group accounted for $58 \%$ of the variation in overall metaphor score, and language group accounted for $1 \%$; for shirt items, age accounted for $47 \%$, whereas language group accounted for $6 \%$.

Thus, subsample analyses yielded results similar to those found in the full-sample analysis. Group factors (i.e., language and SES) played a secondary role to that of age in explaining variation in metaphor interpretation, and group effects were confined to only some metaphor items. Age group accounted for an average of $57 \%$ of the variation in metaphor interpretation (averaged across the subsample analyses reported in this article). By contrast, group factors explained a maximum of $6 \%-9 \%$.

It is interesting to note that effect-size patterns for metaphor and FIT (i.e., mental capacity measured nonverbally) were highly similar. Averaged across the subsample comparisons reported in this article, age group accounted for $55 \%$ of the variation in FIT score, whereas language group and SES group, combined, accounted for less than $1 \%$. These FIT effects are somewhat the result of the study design because the subjects were selected to have age-appropriate FIT scores; however, there was no selection on metaphor score. By contrast, the Woodcock summary score measure of language proficiency yielded a somewhat different pattern of effect sizes. Averaged across the subsample comparisons, age group explained $45 \%$ of the variation in the English Woodcock summary score, whereas language group and SES group, combined, explained 19\%. I examine sources of variance within subsamples next.

Tables 2 and 3 contain across-age correlations for the four subsamples. Again, metaphor score is most highly correlated with the developmental measures. Variance due primarily to developmental differences in linguistic skill and languagerelated knowledge is best reflected in the correlation between metaphor score and the English Woodcock summary score, after mental-capacity score has been partialed out. These partial correlations are $.21(p>.05)$ and $.60(p<.01)$ for the English-speaking middle-class and working-class subsamples, respectively (the corresponding zero-order correlations are .55 and .71); the partial correlations are $.46(p<.01)$ and .01 for the Spanish-English-speaking long-term residents and recent immigrants, respectively (corresponding zero-order correlations are .72 and .51 ). In the recent-immigrant subsample, Spanish proficiency scores correlated more highly with metaphor than did English proficiency scores. Such patterns of cross-language relations are generally taken as evidence that the task performance is controlled more by general cognitive factors (e.g., mental capacity or a store of conceptual knowledge that is detached from lexical labels) than by languagespecific factors (e.g., Cummins, 1984; Grosjean, 1982; Hakuta, 1986; Johnson, 1989, 1991).

\section{Conclusion}

What do the results suggest with regard to the relative roles of linguistic ability, knowledge base, and mental capacity in determining developmental level of metaphor interpretation? One conclusion is that all three factors are relevant, although not in equal degree. The design of the study allowed comparison of the effect of language proficiency with that of general cognitive-developmental factors, such as mental capacity and knowledge repertoire. The developmental curves of metaphor performance for the four subsamples were parallel (see Figure 1 ), which suggests some developmental factor that is independent of sample-based differences in language proficiency or general knowledge. This factor could be a mental-attentional capacity that grows with age in childhood and constrains the complexity level of interpretations that the child

Table 2

Correlation Matrix for the English-Speaking Middle-Class and Working-Class Subsamples

\begin{tabular}{lcccccc}
\hline \multicolumn{1}{c}{ Variable } & 1 & 2 & 3 & 4 & 5 & 6 \\
\hline 1. Metaphor task & - & $.73^{* *}$ & $.64^{* *}$ & $.55^{* *}$ & -.14 & .20 \\
2. Age & $.71^{* *}$ & - & $.74^{* *}$ & $.83^{* *}$ & -.04 & .28 \\
3. FIT & $.50^{* *}$ & $.70^{* *}$ & - & $.68^{* *}$ & .06 & .13 \\
4. Eng sum & $.71^{* *}$ & $.72^{* *}$ & $.55^{* *}$ & - & $.52^{* *}$ & .27 \\
5. Eng std & -.04 & $-.39^{*}$ & -.20 & .33 & - & .10 \\
6. Eng story & .13 & .26 & .16 & $.51^{* *}$ & $.36^{*}$ & - \\
\hline
\end{tabular}

Note. $\quad$ FIT $=$ Figural Intersections Test; Eng = English measure; sum = summary score from the Oral Language subscale of the Woodcock Language Proficiency Battery; std = standard score from the Oral Language subscale of the Woodcock Language Proficiency Battery; story = story-retelling task from the Language Assessment Scales. Correlations for middle-class subsample $(n=31)$ are presented above the main diagonal, and correlations for working-class subsample $(n=34)$ are presented below the main diagonal.

${ }^{*} p<.05 .{ }^{* *} p<.01$. 
Table 3

Correlation Matrix for the Spanish-English-Speaking Long-Term Resident and Recent-Immigrant Subsamples

\begin{tabular}{|c|c|c|c|c|c|c|c|c|c|c|}
\hline Variable & 1 & 2 & 3 & 4 & 5 & 6 & 7 & 8 & 9 & 10 \\
\hline 1. Metaphor task & - & $.77^{* * *}$ & $.69^{* *}$ & $.72^{* *}$ & .16 & $.43^{* *}$ & $.58 * *$ & -.03 & .15 & $.42^{* *}$ \\
\hline 2. Age & $.83^{* *}$ & - & $.72^{* *}$ & $.78^{* *}$ & -.04 & $.36^{*}$ & $.62^{* *}$ & -.21 & -.01 & .25 \\
\hline 3. FIT & $.80^{* *}$ & $.74^{* *}$ & - & $.71^{* *}$ & .18 & $.44^{* *}$ & $.55^{* *}$ & -.02 & .07 & .26 \\
\hline 4. Eng sum & $.51^{*}$ & $.63^{* *}$ & $.63^{* *}$ & - & $.58^{* *}$ & $.51^{* *}$ & $.79^{* *}$ & .22 & .17 & $.55^{* *}$ \\
\hline 5. Eng std & .21 & -.21 & .01 & $.61^{* * *}$ & - & .30 & $.48^{* * *}$ & $.61^{* *}$ & .26 & $.57^{* *}$ \\
\hline 6. Eng story & .34 & .26 & .31 & $.62^{* * *}$ & $.50^{*}$ & - & .31 & .09 & .19 & $.48^{* *}$ \\
\hline 7. Span sum & $.64^{* *}$ & $.72^{* *}$ & $.54^{*}$ & .38 & -.25 & -.02 & - & $.63^{* *}$ & $.34^{*}$ & $.42^{* *}$ \\
\hline 8. Span std & .07 & .03 & .02 & -.07 & -.11 & -.26 & $.70^{* *}$ & - & $.44^{* *}$ & .28 \\
\hline 9. Span story & $.52 *$ & .42 & .39 & .04 & -.33 & -.26 & $.63^{* *}$ & $.47^{*}$ & - & .21 \\
\hline 10. Teach rtg & -.06 & -.04 & .09 & $.51^{*}$ & $.68^{* * *}$ & $.55^{*}$ & -.20 & -.25 & -.08 & - \\
\hline
\end{tabular}

Note. $\quad$ FIT = Figural Intersections Test; Eng = English measure; Span = Spanish measure; sum = summary score from the Oral Language subscale of the Woodcock Language Proficiency Battery; std = standard score from the Oral Language subscale of the Woodcock Language Proficiency Battery; story = story-retelling task from the Lanugage Assessment Scales. Teach rtg = teachers' rating on the Observation Form of the Language Assessment Scales. Correlations for long-term resident subsample (resident 5 years or more; $n=39$ ) are presented above the main diagonal, and correlations for recent-immigrant subsample (resident 3 years or less; $n=21$ ) are presented below the main diagonal.

${ }^{*} p<.05 .{ }^{* *} p<.01$.

can construct. Elsewhere (Johnson et al., 1989; Johnson \& Pascual-Leone, 1989) I presented empirical evidence in support of this hypothesis, and, in the present study, the high correlations between metaphor and a nonverbal measure of mental capacity are consistent with this interpretation.

Because the within-age samples were equal in measured mental capacity, sample differences must be due to differences in language proficiency or in general knowledge. With regard to language proficiency, results of the present study indicate that an effect on metaphor performance at the group level occurs only for some metaphor items; and that even then the group effect is of small magnitude. This result has been replicated subsequently with adult subjects. Johnson and Rosano (1991) found that a sample of adult English-as-a-secondlanguage students (from a variety of language backgrounds) differed from a sample of native English speakers on measures of language proficiency in English but not on level of metaphor interpretation or on a nonverbal measure of analytical ability. Language proficiency scores were uncorrelated with metaphor score in these adult subjects.

Although group membership per se appears to explain little of the variation in level of metaphor interpretation, the correlational data suggest that individual differences in languagerelated knowledge do account for some variance in metaphor within certain groups. In the present study, English proficiency was most related to metaphor score within the Englishspeaking working-class subsample and within the long-termresident Spanish-English subsample (see partial correlations with the English Woodcock Summary Score). In the Englishspeaking middle-class group (which obtained the highest scores on the Woodcock test) and the recent-immigrant Spanish-English group (which obtained the lowest English Woodcock scores), English proficiency was unrelated to metaphor score when mental capacity was partialed out. These results suggest that there may be some middle range of proficiency within which knowledge of language is predictive of level of metaphor interpretation.

The study has little to say about the role of domain-specific knowledge in metaphor development, as depth of knowledge about the specific topic and vehicle domains were not inde- pendently measured. The various topic and vehicle effects may stem in part from developmental factors and in part from domain-specific learning (see Johnson \& Pascual-Leone, 1989, p. 21). The Age $\times$ Topic effect exhibited by the SpanishEnglish-speaking children in the present study has been found previously with monolingual English children (Johnson \& Pascual-Leone, 1989); sampling differences may account for its absence in the present sample of English-speaking children.

The study provides differential data on metaphor interpretation in normally developing children. Results support the generalizability of the proposed developmental model of metaphor comprehension - and the derived method of measuring complexity level-across types of subjects. Metaphor score appears to increase with age cohort in the same way regardless of social class or language-group membership (see Figure 1). These differential factors are not unrelated to level of metaphor interpretation, but they appear to play a secondary role to factors associated with normal development (i.e., mental capacity and relevant experience). Although a complete theory of metaphor comprehension should not ignore linguistic variables, the results provide little support for linguistic skill as a major predictor of developmental change in metaphor interpretation.

Metaphor plays an important role in education, communication, and the acquisition of new knowledge (e.g., Halpern, Hansen, \& Reifer, 1990; Petrie, 1979; Vosniadou, 1987a; Vosniadou \& Schommer, 1988). Results suggest that differential factors (social class and second-language status) should not restrict educational uses of metaphor. In particular, proficiency in English appears not to be a barrier to metaphoric communication in language minority students.

The present results concern basic processes in metaphoric understanding, that is, the ability to produce interpretations at various levels of metaphoric processing. The metaphoric stimuli were deliberately constructed to allow a range of interpretations across the various levels. Developmental variables are the major predictors of level of interpretation with decontextualized metaphors, but differential factors might play an important role in construction of interpretations that are appropriate to a specific context. Future research should 
examine the extent to which differential factors relate to comprehension of contextualized metaphors.

\section{References}

Arlin, P. K. (1978). Piagetian operations in the comprehension, preference and production of metaphors. In R. Weizman, $R$. Brown, P. Levinson, \& P. Taylor (Eds.), Proceedings of the Interdisciplinary Conference on Piagetian Theory and Its Implications for the Helping Professions (Vol. 1, pp. 279-289). Los Angeles: University of Southern California.

Asch, S. E., \& Nerlove, H. (1960). The development of double function terms in children. In B. Kaplan \& S. Wapner (Eds.), Perspectives in psychological theory: Essays in honor of Heinz Werner (pp. 47-60). Madison, CT: International Universities Press.

Baldwin, R. S., Luce, T. S., \& Readence, J. E. (1982). The impact of subschemata on metaphorical processing. Reading Research Quar. terly, 17, 528-543.

Ben-Zeev, S. (1977). Mechanisms by which childhood bilingualism affects understanding of language and cognitive structures. In P. Hornby (Ed.), Bilingualism: Psychological, social, and educational implications (pp. 29-55). San Diego, CA: Academic Press.

Bernstein, B. (1971). Class, codes, and control: Vol. 1. Theoretical studies towards a sociology of language. London: Routledge \& Kegan Paul.

Billow, R. M. (1975). A cognitive developmental study of metaphor comprehension. Developmental Psychology, 11, 415-423.

Boswell, D. (1979). Metaphoric processing in the mature years. $\mathrm{Hu}$ man Development, 22, 373-384.

Bountrogianni, M. (1984). A cross-cultural study of children's metaphoric capacity. Paper presented at the meeting of the Society for Research in Child Development, Toronto.

Case, R. (1975). Social class differences in intellectual development: A neo-Piagetian investigation. Canadian Journal of Behavioural Science, 7, 244-261.

Case, R. (1985). Intellectual development: Birth to adulthood. San Diego, CA: Academic Press.

Cometa, M. S., \& Eson, M. E. (1978). Logical operations and metaphor interpretation: A Piagetian model. Child Development, 49, 649-659.

Corson, D. (1989). Adolescent lexical differences in Australia and England by social group. Journal of Educational Research, 82, 146-157.

Cummins, J. (1981). Age on arrival and immigrant second language learning in Canada: A reassessment. Applied Psycholinguistics, 11, 132-149.

Cummins, J. (1984). Bilingualism and special education: Issues in assessment and pedagogy. San Diego, CA: College-Hill Press.

De Avila, E. A., \& Duncan, S. E. (1983). Language Assessment Scales (LAS). San Rafael, CA: Linguametrics Group.

De Avila, E. A., Havassy, B., \& Pascual-Leone, J. (1976). MexicanAmerican schoolchildren: $A$ neo-Piagetian approach. Washington, DC: Georgetown University Press.

de Ribaupierre, A., \& Pascual-Leone, J. (1979). Formal operations and $M$ power: A neo-Piagetian investigation. New Directions for Child Development, 5, 1-43.

Diaz, R. (1983). Thought in two languages: The impact of bilingualism on cognitive development. Review of Research in Education, 10, 23-54.

Dickinson, D. K., \& Snow, C. E. (1987). Interrelationships among prereading and oral language skills in kindergarteners from two social classes. Early Childhood Research Quarterly, 2, 1-25.

Farran, D. (1982). Mother-child interaction, language development, and the school performance of poverty children. In L. Feagans \&
D. Fagan (Eds.), The language of children reared in poverty (pp. 19-52). San Diego, CA: Academic Press.

Feagans, L. (1982). The development and importance of narratives for school adaptation. In L. Feagans \& D. Fagan (Eds.), The language of children reared in poverty (pp. 95-116). San Diego, CA: Academic Press.

Gardner, H. (1974). Metaphors and modalities: How children project polar adjectives onto diverse domains. Child Development, 45, 8491.

Gardner, H., Winner, E., Bechhofer, R., \& Wolf, D. (1978). The development of figurative language. In K. E. Nelson (Ed.), Children's language (Vol. 1, pp. 1-37). New York: Gardner Press.

Gentner, D. (1977). Children's performance on a spatial analogies test. Child Development, 48, 1034-1039.

Gentner, D. (1988). Metaphor as structure mapping: The relational shift. Child Development, 59, 41-59.

Globerson, T. (1983). Mental capacity and cognitive functioning: Developmental and social class differences. Developmental Psychology, 19, 225-230.

Grosjean, F. (1982). Life with two languages. Cambridge, MA: Harvard University Press.

Hakuta, K. (1986). Mirror of language: The debate on bilingualism. New York: Basic Books.

Halpern, D. F., Hansen, C., \& Reifer, D. (1990). Analogies as an aid to understanding and memory. Journal of Educational Psychology, 82, 298-305.

Heath, S. B. (1982). What no bedtime story means: Narrative skills at home and school. Language and Society, 11, 49-76.

Heath, S. B. (1983). Ways with words. Cambridge, England: Cambridge University Press.

Hess, R. D., \& Shipman, V. C. (1965). Early experience and the socialization of cognitive modes in children. Child Development, 36, 869-886.

Hessler, G. (1982). Use and interpretation of the Woodcock-Johnson Psychoeducational Battery. Hingham, MA: Teaching Resources.

Holobow, N. E., Genesee, F., Lambert, W. E., Gastright, J., \& Met, M. (1987). Effectiveness of partial French immersion for children from different social class and ethnic backgrounds. Applied Psycholinguistics, 8, 137-152.

Johnson, J. (1982). The figural intersections test (FIT): A measure of mental attentional energy. Unpublished manuscript, York University, Department of Psychology, Toronto.

Johnson, J. (1987). [Developmental data on metaphor interpretations by school children in California]. Unpublished raw data.

Johnson, J. (1989). Factors related to cross-language transfer and metaphor interpretation in bilingual children. Applied Psycholinguistics, 10, 157-177.

Johnson, J. (1991). Constructive processes in bilingualism and their cognitive growth effects. In E. Bialystok (Ed.), Language processing in bilingual children (pp. 193-221). Cambridge, England: Cambridge University Press.

Johnson, J., Fabian,V., \& Pascual-Leone, J. (1989). Quantitative hardware-stages that constrain language development. Human Development, 32, 245-271.

Johnson, J., \& Pascual-Leone, J. (1989). Developmental levels of processing in metaphor interpretation. Journal of Experimental Child Psychology, 48, 1-31.

Johnson, J., \& Rosano, T. (1991). Metaphor interpretation in adult second language learners: Linguistic and stylistic factors. Manuscript submitted for publication.

Jones, J., \& Stone, C. A. (1989). Metaphor comprehension by language learning disabled and normally achieving adolescent boys. Learning Disability Quarterly, 12, 251-260.

Kahneman, D. (1973). Attention and effort. Englewood Cliffs, NJ: Prentice-Hall. 
Keil, F. C. (1986). Conceptual domains and the acquisition of metaphor. Cognitive Development, 1, 73-96.

Kogan, N. (1983). Stylistic variation in childhood and adolescence: Creativity, metaphor, and cognitive styles. In J. Flavell \& E. Markman (Eds.), Handbook of child psychology: Vol. 3. Cognitive development (pp. 630-706). New York: Wiley.

Laosa, L. M. (1978). Maternal teaching strategies in Chicano families of varied educational and socioeconomic levels. Child Development, 49, 1129-1135.

Laosa, L. M. (1980). Maternal teaching strategies in Chicano and Anglo-American families: The influence of culture and education on maternal behavior. Child Development, 51, 759-765.

Marks, L., Hammel, R., \& Bornstein, M. (1987). Perceiving similarity and comprehending metaphor. Monographs of the Society for Research in Child Development, 52(1, Serial No. 215).

Miller, M. (1980). Executive schemes vs. mental capacity in predicting intellectual underperformance among lower socioeconomic status groups. Unpublished doctoral dissertation, York University, Toronto.

Miller, R., Pascual-Leone, J., Campbell, C., \& Jukes, T. (1989). Crosscultural similarities and differences on two neo-Piagetian cognitive tasks. International Journal of Psychology, 24, 293-313.

Niaz, M., \& Lawson, A. (1985). Balancing chemical equations: The role of developmental level and mental capacity. Journal of Research in Science Teaching, 22, 41-51.

Nippold, M. A., \& Fey, S. H. (1983). Metaphoric understanding in preadolescents having a history of language acquisition difficulties. Language, Speech, and Hearing Services in Schools, 14, 171-180.

Ogbu, J. U. (1981). Origins of human competence: A culturalecological perspective. Child Development, 52, 413-429.

Ogbu, J. U. (1985). Research currents: Cultural-ecological influences on minority school learning. Language Arts, 62, 860-869.

Ortony, A., Reynolds, R., \& Arter, J. (1978). Metaphor: Theoretical and empirical research. Psychological Bulletin, 85, 919-943.

Palermo, D. (1986). From the marble mass of language, a view of the developing mind. Metaphor and Symbolic Activity, 1, 5-23.

Parkinson, G. (1975). The limits of learning: A quantitative investigation of intelligence. Unpublished doctoral dissertation, York University, Toronto.

Pascual-Leone, J. (1970). A mathematical model for the transition rule in Piaget's developmental stages. Acta Psychologica, 32, 301345.

Pascual-Leone, J. (1980). Constructive problems for constructive theories: The current relevance of Piaget's work and a critique of information-processing simulation psychology. In R. Kluwe \& $\mathrm{H}$. Spada (Eds.), Developmental models of thinking (pp. 263-296). San Diego, CA: Academic Press.

Pascual-Leone, J. (1984). Attention, dialectic, and mental effort: Towards an organismic theory of life stages. In M. Commons, F. Richards, \& C. Armon (Eds.), Beyond formal operations: Late adolescent and adult cognitive development (pp. 182-215). New York: Praeger.

Pascual-Leone, J. (1987). Organismic processes for neo-Piagetian theories: A dialectical causal account of cognitive development. International Journal of Psychology, 22, 531-570.

Pascual-Leone, J., \& Burtis, J. (1975). Manual for FIT: Figural intersections test. Unpublished manuscript, York University, Department of Psychology, Toronto.

Pascual-Leone, J., \& Goodman, D. (1979). Intelligence and experience: A neo-Piagetian approach. Instructional Science, 8, 301-367.

Pascual-Leone, J., \& Ijaz, H. (1989). Mental capacity testing as a form of intellectual-developmental assessment. In R. Samuda, S. Kong, J. Cummins, J. Lewis, \& J. Pascual-Leone(Eds.), Assessment and placement of minority students (pp. 143-171). Toronto, Ontario, Canada: C.J. Hogrefe.
Pascual-Leone, J., \& Johnson, J. (in press). The psychological unit of developmental processes and its role in task analysis: A reinterpretation of object permanence. In M. Chapman \& M. Chandler (Eds.), Criteria for competence: Controversies in the assessment of children's abilities. Hillsdale, NJ: Erlbaum.

Pascual-Leone, J., \& Smith, J. (1969). The encoding and decoding of symbols by children: A new experimental paradigm and a neoPiagetian model. Joumal of Experimental Child Psychology, 8, 328-355.

Petrie, H. G. (1979). Metaphor and learning. In A. Ortony (Ed.), Metaphor and thought (pp. 438-461). Cambridge, England: Cambridge University Press.

Pollio, M. R., \& Pickens, J. D. (1980). The developmental structure of figurative competence. In R. Honeck \& R. Hoffman (Eds.), Cognition and figurative language (pp. 311-340). Hillsdale, NJ: Erlbaum.

Rackstraw, S. J., \& Robinson, W. P. (1967). Social and psychological factors related to variability of answering behaviour in five-yearold children. Language and Speech, 10, 88-106.

Reynolds, R., \& Ortony, A. (1980). Some issues in the measurement of children's comprehension of metaphorical language. Child Development, 51, 1110-1119.

Seidenberg, P. L., \& Bernstein, D. K. (1986). The comprehension of similes and metaphors by learning-disabled and nonlearning-disabled children. Language, Speech, and Hearing Services in Schools, 17, 219-229.

Slaughter-Defoe, D. T., Nakagawa, K., Takanishi, R., \& Johnson, D. J. (1990). Toward cultural/ecological perspectives on schooling and achievement in African- and Asian-American children. Child Development, 61, 363-383.

Snow, C. E., Arlman-Rupp, A., Hassing, Y., Jobse, J., Joosten, J., \& Vorster, J. (1976). Mothers' speech in three social classes. Journal of Psycholinguistic Research, 5, 1-20.

Statistics Canada. (1988). Census Canada 1986 profiles: Census tracts Toronto, Part 2. Ottawa, Ontario, Canada: Author.

Tough, J. (1982). Language, poverty, and disadvantage in school. In L. Feagans \& D. Fagan (Eds.), The language of children reared in poverty (pp. 3-18). San Diego, CA: Academic Press.

Tourangeau, R., \& Sternberg, R. J. (1982). Understanding and appreciating metaphors. Cognition, 11, 203-244.

Vosniadou, S. (1987a). Children and metaphors. Child Development, $58,870-885$.

Vosniadou, S. (1987b). Contextual and linguistic factors in children's comprehension of nonliteral language. Metaphor and Symbolic Activity, 2, 1-11.

Vosniadou, S., \& Ortony, A. (1983). The emergence of the literalmetaphorical-anomalous distinction in young children. Child Development, 54, 154-161.

Vosniadou, S., \& Ortony, A. (1986). Testing the metaphoric competence of the young child: Paraphrase vs. enactment. Human Development, 29, 226-230.

Vosniadou, S., Ortony, A., Reynolds, R., \& Wilson, P. (1984). Sources of difficulty in the young child's understanding of metaphorical language. Child Development, 55, 1585-1606.

Vosniadou, S., \& Schommer, M. (1988). Explanatory analogies can help children acquire information from expository text. Journal of Educational Psychology, 80, 524-536.

Waggoner, J., \& Palermo, D. (1989). Betty is a bouncing bubble: Children's comprehension of emotion-descriptive metaphors. Developmental Psychology, 25, 152-163.

Wells, G. (1981). Learning through interaction: The study of language development. Cambridge, England: Cambridge University Press.

Whyte, J. (1983). Metaphor interpretation and reading ability in adults. Journal of Psycholinguistic Research, 12, 457-465.

Winner, E. (1988). The point of words: Children's understanding of 
metaphor and irony. Cambridge, MA: Harvard University Press.

Winner, E., Engel, M., \& Gardner, H. (1980). Misunderstanding metaphor: What's the problem? Journal of Experimental Child Psychology, 30, 22-32.

Winner, E., Rosenstiel, A. K., \& Gardner, H. (1976). The development of metaphoric understanding. Developmental Psychology, 12, 289-297.

Winner, E., Wapner, W., Cicone, M., \& Gardner, H. (1979). Measures of metaphor. New Directions for Child Development, 6, 67-75.
Woodcock, R. W. (1980). Woodcock Language Proficiency Battery, English form. Hingham, MA: Teaching Resources.

Woodcock, R. W. (1981). Woodcock Language Proficiency Battery, Spanish form. Hingham, MA: Teaching Resources.

Received July 25,1990

Revision received July 9, 1991

Accepted July 9, 1991

\section{Low Publication Prices for APA Members and Affiliates}

Keeping You Up to Date: All APA members (Fellows, Members, and Associates, and Student Affiliates) receive--as part of their annual dues--subscriptions to the American Psychologist and the APA Monitor.

High School Teacher and Foreign Affiliates receive subscriptions to the APA Monitor and they can subscribe to the American Psychologist at a significantly reduced rate.

In addition, members and affiliates are eligible for savings of up to $60 \%$ on other APA joumals, as well as significant discounts on subscriptions from cooperating societies and publishers (e.g., the British Psychological Society, the American Sociological Association, and Human Sciences Press).

Essential Resources: APA members and affiliates receive special rates for purchases of APA books, including Computer Use in Psychology: A Directory of Software, the Master Lectures, and Journals in Psychology: A Resource Listing for Authors.

Other Benefits of Membership: Membership in APA also provides eligibility for low-cost insurance plans covering life; medical and income protection; hospital indemnity; accident and travel; Keogh retirement; office overhead; and student/school, professional, and liability.

For more information, write to American Psychological Association, Membership Services, 1200 Seventeenth Street NW, Washington, DC 20036, USA or call (703) $247-7760$ (collect calls cannot be accepted). 